\title{
Brighton, 1971
}

The United Kingdom was host nation to the Seventh European Rheumatology Congress which was held at Brighton in June and attended by nearly 1,500 participants and accompanying persons.

A new type of scientific programme had been adopted by the organizing committee. Of the 543 abstracts submitted and accepted only a minority were read as free papers in the traditional style. The rest were grouped into symposia or round table discussions. At each of these sessions three introductory papers reviewed the substance of the abstracts, and in the following discussions participants were limited to only two minutes for comments on their own work or that of others. Thus most contributors did not present their material in the usual way: only 75 authors read free communications and 109 gave introductory papers. All the abstracts have, however, been published in the Abstract Handbook of the Congress.*

Another feature of the Congress was a daily lecture given by an eminent invited guest, and two of these form the opening papers in this issue of the Annals. Each represents an area of current development in rheumatology. One is the increasing application of surgery to the alleviation of chronic rheumatic diseases, to which nobody has contributed more than Mr. John Charnley of Manchester, who writes on 'The Present Status of Total Hip Replacement'. The impact of immunology on the study of rheumatoid arthritis was illustrated by much of the work presented at the Congress, and the second paper, 'Antigen Recognition by T-Cells and its Suppression', is by the distinguished French immunologist Dr. Jean-François Bach.

The experiment was an interesting one and marks a step forward in the evolution of scientific conferences. Symposia in which able chairmen and introductory speakers had prepared their ground well were highly successful, although other sessions were less happy. It is good to know that the Congress committee is preparing to hand on its experience to other future organizers, so improving still further our efforts to communicate with one another sensibly and succinctly.

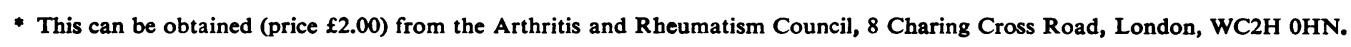

